\title{
PROLEGOMENA OVER EXEGESE EN DOGMATIEK
}

Het is gemakkelijk een theorie op te stellen over de verhouding, die zou behooren te bestaan tusschen exegese en dogmatiek. Toetst men zulke theorieën aan wat er in werkelijkheid gebeurt, dan is de uitslag onbevredigend. Ons onderwerp is, m.i., te vergelijken met de taak om in een voordracht van normale lengte aan een gehoor, dat slechts die kennis van zaken heeft, die aan een gewoon beschaafd mensch eigen is, duidelijk te maken, b.v. wat de verhouding is van de interne gesteldheid van het Chineesche Rijk tot het geheel van de machten rondom de Stille Zuidzee en dat dan gezien in het verband van de laatste vier eeuwen.

Immers wat men onder het woordje Dogmatiek samenvat is een onderwerp, waarin geestelijke machten van verschillende structuur en grootte betrokken zijn, evenals dat het geval is bij het probleem ChinaPacific. Zelfs voor Rusland, dat in twee systemen tegelijk is betrokken, zou men een parallel kunnen vinden! En wat men Exegese noemt heeft als achtergrond een rijkdom en verscheidenheid van hulpbronnen, heeft te maken met zóóveel dingen van zielkundigen aard - zelfs met massapsychologie -; er is ook zóóveel materieels mee gemoeid, dat de vergelijking tusschen den factor "exegese" eenerzijds en "machten rondom de Stille Zuidzee" andererzijds ook niet misplaatst is. Prolegomena zijn dus geen overbodige weelde.

Uit de woorden exégeisthai en dgl. is helaas niets af te leiden. Hun beteekenis is in het Grieksche taalgebruik onscherp gebleven. Zoo rijst dan de vraag: is het bij ons beter gesteld? Is ,exégese" b.v. hetzelfde als ,uitlegging"? Wat beteekent eigenlijk ,verklaren”, want ook dat woord wordt vaak gebezigd!

Ik zou voorstellen er erg voorzichtig mede te zijn en liefst dit woordje in 't geheel niet te gebruiken. Immers, ,verklaren" is de grondgedachte der natuurwetenschappen, die altijd bezig zijn met „oorzakelijke verklaringen" van verschijnselen op grond van z.g. natuurwetten. Den Bijbel te „verklaren" is dus een uitdrukking, die heel licht tot onjuiste gedachten aanleiding geeft! Ook met het wijsgeerig gebruik van dat woord is het niet beter gesteld.

Daar beteekent het, dat men gedachtencomplexen weet in te voegen in het patroon van bepaalde gedachtengangen, wat een heel ingewikkeld en meest moeilijk te volgen proces is. Laten wij dus het woord ,verklaren" als term voor Exegese terzijde leggen.

Wat echter is het onderscheid tusschen Exegese e $\mathrm{n}$ it l e g ging? Exegese is de kunst van den exegeet, uitlegging 
die van den interpretator, maar het eerste is het fundament van het tweede. De uitlegger kan niet beginnen als de exegeet hem niet het pad heeft gebaand. Immers, de e $x$ e g e e $t$ is - ambtshalve - een $1 \mathrm{u}$ i s t e$\mathrm{r}$ a a r. Hij tracht met behulp van zijn bizondere begaafdheid en zijn gespecializeerde kennis a lles te vernemen wat de auteur met dézen text heeft willen zeggen, maar tevens ook alles wat diens lezers uit dien text hebben kunnen verstaan. Op den toeschouwer maakt hij soms den indruk van een on t e k ker.

De u itlegger is heel wat anders: hij is - ambtshalve-een spreker. Zijn gave is het om uit hetgeen de-exegeet aan het licht bracht zulk een keuze te doen, dat hij, als bemiddelaar, aan hedendaagsche lezers datgene geeft wat zij juist weten moeten om de bedoeling van den auteur (dien zij meestal slechts in een vertaling kunnen lezen,) niet verkeerd op te vatten. De uitlegger is tenslotte een $\mathrm{v}$ e $\mathrm{r}$ e $\mathrm{ll} \mathrm{le} \mathrm{r}$.

Tot wien van de twee moet nu de dogmaticus zich wenden? Maar, zóó eenvoudig is de vraag niet eenmaal! Zoowel de exegeet als de uitlegger hebben denkelijk een eigen dogmatiek. Bouwt men ooit Reformatorische dogmatiek op Roomsche uitlegging? Natuurlijk moet men de w a $\mathrm{r}$ he id kiezen en waarborgen zien te verkrijgen voor een zoo objectief mogelijke exegese en uitlegging. Om daarin echter een inzicht te bekomen, moeten wij het werk van onze helpers nader bezien en beter begrijpen.

De gespecializeerde kennis van den e $\mathrm{x}$ e g e e $\mathrm{t}$ moet méér omvatten dan een zoo grondig mogelijke kennis van de taal of de talen, die zijn text betreffen. Bij het N.T. is dat b.v. niet alleen het Grieksch (het late Koinè-Grieksch), waarin het geschreven is, maar ook het Arameesch, de Semitische taal, waarin het vaak gedacht is! Dat is al heel wat, maar het werk eischt méér! Alles wat binnen het geestelijk gezichtsveld van den oorspronkelijken auteur of van diens lezers viel, moet hij minstens kúnnen zien. Hij is de man, die heeft te onderscheiden w a $t$ zich daaronder bevindt, dat kon hebben ingewerkt naar vorm of naar inhoud, wellicht zelfs in beide opzichten, op de uitingen van den auteur. Het is een der moeilijkste deelen van zijn taak om te beslissen wát inderdaad gewerkt heeft. Hij moet met zijn wetenschappelijk geweten uitmaken, hoe ver, naar zijn beste oordeel, die invloed in werkelijkheid heeft gestrekt!

Doch de u i t leggè r heeft het ook zoo gemakkelijk niet! Hij moet de geheimen van zijn eigen taal en al de kronkelpaden van den geest zijner tijdgenooten, die op die taal reageeren in hun onbewuste denken, door en door kennen. Hún voorstellingsmateriaal en húnne denkgewoonten zijn de hulpmiddelen, waarmede hij hén moet laten begrijpen wat de auteur, naar zijn oordeel, eigenlijk aan hen heeft te zeggen! Voor die moeilijkheid staat ieder predikant: ieder prediker is een uitlegger! 
Het groote risico van den uitlegger is altijd weer, dat zijn lezers of hoorders uit zijn uitlegging dingen gaan afleiden, die hij niet op rekening van den auteur, dien hij verklaart, $\mathrm{mag}$ laten schrijven.

Het onderscheid tusschen exegese en uitlegging is dus $\mathrm{n} i \mathrm{et}$ het onderscheid tusschen een z.g. wetenschappelijken Commentaar en een „practische” uitlegging van een Evangelie of een Brief! Veel karakteristieker dan dit onderscheid is het feit, dat de exegeet $z i j n$ gelaat richt naar het verleden, terwijl de uitleggerden blik richtopzijngehoorin het heden.

De beste exegeet behoeft dus nog niet de beste uitlegger te wezen, maar wel zal de beste uitlegger altijd nog een behoorlijk exegeet moeten zijn. In de groote „commentaren" vindt men meestal enkel „exegese”; de uitlegging komt daarbij in den regel veel te kort. Omgekeerd echter vindt men in veel van wat zich als "uitlegging" presenteert een exegese, die niet in orde is. Dat niet in orde zijn wordt dan vaak bemanteld door een voortdurend gepraat over hedendaagsche, nieuwe en nieuwste Dogmatiek. Dat gebeurt links en ook ter rechterzijde: peccatur intra muros et extra.

Waaraan ligt dat? Aan het persoonlijk element, dat van oudsher erkend is geworden met den eisch van ,exegese e mente auctoris", korter gezegd met den eisch van congenialiteit. Auteur en tusschenpersoon moeten congeniaal, moeten geestverwant zijn, wil er van het werk iets betrouwbaars terecht komen.

Ieder geschrift immers van eenige betekenis bevat niet alleen geformuleerde gedachten, maar ook ongeformuleerde, die men "tusschen de regels" moet kunnen lezen. Immers, i e $m$ a $\mathrm{n} d$ heeft dat alles door het medium van zijn persoonlijkheid heen gedacht en neergeschreven. De simpele goede trouw eischt, dat wij daarmee rekenen en alles in rekening brengen wat wij vermoeden, dat den auteur heeft bewogen.

Het groote waagstuk en het groote vraagstuk is evenwel, of $w i j$ in zijne gedachten en in haren samenhang voldoende in kunnen komen.

Onder tijdgenooten is dat vaak al een lastig werk. Ook al hebben wij dezelfde taal, dezelfde wereld van voorstellingen en dezelfde algemeene sfeer van gedachten, zoo blijven er toch altijd nog $\mathrm{d} r \mathrm{i}$ e eischen gelden: (1) hef onderwerp moet ons eenigszins bekend zijn, (2) onze geest moet niet al te vreemd zijn aan de manier van denken van den auteur, (3) wij moeten ons bewust én onbewust, eenigermate kunnen verplaatsen in dien eigenaardigen persoon van den schrijver of spreker.

Dat alles wordt natuurlijk veel moeilijker met de Apostelen en Evangelisten, die, eeuwen geleden, in eene Joodsch-Grieksch-Oostersche wereld leefden, en die het woord richtten tot menschen in $\mathrm{d}$ i e wereld, geboren Joden of zelfs heidenen!

Onze gave van begrijpen en vertolken moet dus door studie en opmerkingsvermogen zóó ontwikkeld worden, dat wij niet door onvol- 
doende vakkennis als theologen of door eene - wellicht onbewuste eigenwilligheid den auteur tot getuige zouden maken van gedachten, die hij $n$ i e $t$ gehad heeft. Dat mag niet, en op dát punt moet $z$ e $k$ e rh e i d bestaan! Hier raakt het vraagstuk der juiste exegese direct het probleem van de mogelijkheid van werkelijk schriftuurlijke dogmatiek.

Hoe komt men nu aan die zekerheid? Taalkundige en andere zakelijke kennis brengen ons uitteraard reeds een heel eind verder, maar als zoodanig waarborgen zij toch niet, dat werkelijke congenialiteit aanaanwezig is! Men kan een voortreffelijk kenner zijn van de apostolische taal en haar milieu, men kan voorzien zijn van uitgezochte geleerdheid omtrent allerlei, dat ter zake dient, maar toch verstoken van alle geestverwantschap met het N.T.

Tenslotte ligt de zaak hier zóó, dat men op een gegeven oogenblik verplicht is te $\mathrm{ki} z \mathrm{en}$ en aan een bepaalden exegeet of uitlegger vertrouwen te schenken. De gronden voor dat vertrouwen liggen dan - ten laatste -in den per s o o n van den exegeet én in het resultaat van zijn arbeid. Daarbij is ook de dogmatiek in het spel. Dat is onvermijdelijk, maar in hoeverre? Het is psychologisch onvermijdelijk, dat b.v. de omstandigheid, dat zijne dogmatiek de ónze en niet b.v. de Roomsche of een andere zou zijn, ons niet de neiging zou inboezemen om hem meer te vertrouwen dan een ander. Echter, dit staat volkomen vast voor ieder, die niet in zelfbedrog vervallen wil, die overeenkomst bewijst niet, dat ónze dogmatiek de Schrift inderdaad getrouw zou weergeven!

Op vasteren grond brengt ons het volgende: zoowel de exegeet als de uitlegger moeten, zal hun werk objectief goed zijn, $v r i j z i j n$ $\mathrm{v}$ a $\mathrm{n}$ a $11 \mathrm{e}$ ijdelheid, eigenwilligheid, doordrijverij en effectbejag. Het eerste is voor den philoloog het groote, vaak onbewuste gevaar, zooals het tweede, de eigenwilligheid, dat is voor den historicus, het derde de valstrik van den dogmaticus en het vierde, het effectbejag, de groote verleiding voor den uitlegger, onverschillig of hij op den kansel staat of achter den katheder.

Wat het resultaat betreft, blijkt de qualiteit uit zijn verhelderende werking, zelfs dan als het aantoont, dat de auteur zèlf zijn onderwerp niet tot de laatste helderheid heeft dóórgedacht.

Doch on s oordeel over die verhelderende werking eischt van óns ook nog wel het een en ander! Allereerst moeten wij werkelijk on t$\mathrm{v}$ a nkelijk staan tegenover hetgeen de Schrift zegt: wij moeten werkelijk luisteren en niet tegelijk met een half oor hangen aan het gefluister van een grammophoon, die ons voortdurend de redeneeringen van onze dogmatiek voorzegt, hoe eerbiedwaardig en klemmend die ook wezen mogen. Dat lijkt bijna onmogelijk, maar het kan, mits men het onderscheid tusschen het Bijbelsche denken en het Grieksch. Westersch denken, dat het dialect onzer dogmatieken is, goed heeft gevat en in zich heeft opgenomen.

Teo. 3 
Laat ons toch nimmer vergeten, dat onze Westeuropeesche geest ook in Afrika - tot in den wortel anders is dan die, welke de typisch Duitsche theologische probleemstellingen beheerscht en ook voortbrengt! Het Duitsche philosofische ,idealisme" is import en heeft hier nooit wortel geslagen. Dat kon ook niet, omdat ons het geloof in het alvermogen der z.g. Rede en het vertrouwen in een mystiek vermogen van de menschelijke ziel als deel eener alomvattende albezieling ontbreekt. De taal, die wij spreken en de cultuur, die haar vormde, dankt veel meer aan het Zuiden dan aan Midden-Europa. Van den typisch Nederlandschen geest kan men-cum grano salis-zeggen, dat hij van nature "calvinist" is. Door eeuwenlange „democratie" in polderbestuur en kerkeraden, door de tallooze kleine steden, door het ontbreken van alle soldateske oorlogsverheerlijking, door het vroegtijdig verdwijnen van een heerschenden adel, heeft de Nederlandsche mensch een geheel ander type dan zijn Oosterburen. Ook is ten onzent de Fransche geest een factor van zeer diepgaande beteekenis! Terwijl de Duitschers Hegel en Schelling lazen en Pruisen zich opmaakte tot zijn grooten slag (in 1870) en zijn verdere carrière, las men hier zelfs Goethe nauwelijks, terwijl b.v. Victor Hugo algemeen bekend was. Wanneer onze dogmatici oproepen tot een terugkeer $\mathrm{naar} d \mathrm{e}$ Reformatorische geestesgesteldheid en daardoor het probleem Exegese en Dogmatiek acuut wordt - zooals het behoort te zijn! -, zal men goed doen, dat te ondernemen op Nederlandsche wijze! Calvijn was géén "Duitsche" geest en de groote worsteling met de Roomsche "theologie", die voor de deur staat en die goen kinderspel zal worden, is een strijd met Latijnsche geesten! Niet met Albertus Magnus of met Ekkehard of de Teologia Deutsch zullen wij te maken krijgen, doch met Thomas van Aquino. Niet met "Logik", maar met een logica, die scherp en helder denkt! Wij zullen als theologen wel wat anders te doen krijgen dan ons bezig te houden met het ontwarren van Germaansche complexen, waarin wijsbegeerte en Schriftgetuigenis saamgekluwd zijn. Onze groote kracht zal moeten liggen in een technisch onweerstaanbare exegese en een victorieuze, onweerlegbaar Bijbelsche interpretatie.

Wij keeren terug tot de vraag naar het onderscheid tusschen het Bijbelsche en het Grieksch-Westersche denken, omdat die vraag fundamenteel is en de zekerheid van het resultaat van onzen arbeid raakt.

Wat is het karakteristieke van het Bijbelsche denken? Let wel, wij vragen niet naar een „definitie" van dat denken, maar naar kenteekenen, die het karakterizeeren. Dat is reeds kenmerkend voor de sfeer, die wij willen ingaan. Het volgende moet, m.i., genoemd worden:

(1) God wordt als ha ndelende Wil altijd, in iedere redeneering, meegedacht. 
(2) Nòch het subject, dat denkt, nòch het object, dat overdacht wordt, ziet men als geïsoleerd.

Die twee charakteristica, die saamhangen, vormen den dynamischen kant van het Bijbelsche denken.

(3) Het Bijbelsche denken heeft een afkeer van „definities” en werkt met "qualificaties". Dit laatste is, als men het eenmaal gezien heeft, de meest opvallende eigenaardigheid ervan en, oppervlakkig gesproken, het meest opmerkelijke.

Samenvattend kan men het zóó zeggen: het Bijbelsche denken gelijkt op een $r$ e p o r tag e van op het slagveld, waarbij hoogstens de verborgenen bedoelingen der Generale Staven van beide partijen aanleiding geven tot speculaties, het Grieksch-Westersche denken gelijkt op een $\mathrm{r}$ a p p o r t uit een laboratorium, dat speculeert over z.g. oorzaken en onderstelde wetmatigheden, maar dat over laatste oorzaken consequent zwijgt, omdat het zijn voorwerp heeft geisoleerd.

$W_{i j}$ staan nog even stil bij het derde: afkeer van definitie en voorkeur voor qualificatie. Wanneer gij een definitie van ,gerechtigheid" het Grieksche dikaiosyne - in het N.T. zoudt zoeken, komt gij met leege handen thuis. Hetzelfde overkomt $u$, wanneer gij een definitie zoekt van het tegendeel, de hamartia, de zonde! Waarom?

Wie een zaak wil „definieeren”, moet haar isoleeren, moet haar "fines", hare vaste grenzen overzien, moet bo v e n haar staan. Uit Bijbelsch oogpunt is dat hybris, d.w.z. een hoogmoed, waarbij de mensch tracht te grijpen wat niet voor hem is weggelegd. Immers, dit isoleeren beteekent allereerst al, dat men zijn onderwerp losmaakt van God als den altijd actieven Wil! Bovendien neemt men dan aan, dat ons redelijk vermogen óók in zulk een, soortgelijk, isolement werkt.

Wat de mensch echter wél doen mag en ook doen kán, is op de teekenen letten, de kenmerken opmerken en onderscheiden, die een qualificatie verraden in hetgeen hij waarneemt. Zoo zegt Paulus b.v. van de hamartia, dat zij is echthra eis Theon, d.w.z. instinctieve afkeerigheid naar den kant van God. Overal waar gij die „echthra" ontmoet, hebt gij te maken met de werking der Hamartia.

Zulk een "qualificatie" is als een vlag, die op een schip geheschen wordt; zij zegt iets belangrijks over dat vaartuig, maar niet alles! Op hetzelfde schip kan straks ook een andere waaien, de reederijvlag b.v., die weer op iets anders de aandacht vestigt. Het een is geen tegenspraak van het ander! Wanneer Paulus b.v. zegt, dat "de Heer is de Geest", is dat geen "definieerende" uitspraak, die de tweede en derde persoon der Drieëenheid verwart, maar een qualificatie: in de geestelijke werkelijkheid, die hij voor oogen had, had de activiteit van Christus de qualiteit, die tot het gebruik van het woord „pneuma" noopte. Paulus is ook $\mathrm{n}$ i e $\mathrm{t}$ met zichzelf in tegenspraak en lijdt niet aan een gemis van ,die eigentlich systematische Begabung", wanneer hij spreekt van Christus „, i n ons" èn van een leven van den Christen „in Christus”. Logisch 
is dat tegenspraak: de eene definitie zou de andere uitsluiten. Het zijn echter ,qualificaties": de waarneming van Christus' activiteit dwong den eenen keer tot deze, den anderen keer tot gene uitspraak.

Wie dit verder nagaat en het karakteristieke van het Bijbelsche denken ten volle recht doet wedervaren ten aanzien van exegese en dogmatiek beide, ervaart, dat hij een zware taak heeft ondernomen! Want dit gaat ons dwars tegen den draad! Ons Grieksch-Westersche denken, dat ook het geestelijk dialect onzer dogmatieken heeft gevormd, bevat een wrong, een stuwing, die daar niet evenwijdig mede loopt.

Want het Grieksche denken is van natu urwete $\mathbf{n s c h}$ app elijken oorsprong. Het beschreef het Heelal als de manifestatie van een oorspronkelijk ,Het”, van een groote „X"! Die „X”, dat "Het" is n i m m e r werkelijk een Wil! God, of wat dan ",godheid" heet, is steeds een „Het”, nooit in werkelijkheid een „Hij”. Het Grieksche denken isoleert zijn objecten. Het onderstelt, d.w.z. het neemt als geloofsartikel aan, dat die objecten hun geheim bij ontleding prijs zullen moeten geven. Het gelooft, dat er geen a $\mathrm{n} d$ e $\mathrm{r}$ e geheimen bestaan of bestaan kunnen dan die met zulk een analyse zijn op te sporen (alsof iemand, die een piano uit elkaar neemt, zoodoende ooit achter de negende symphonie van Beethoven zou komen!). Het gelooft dan ook in ,definities" èn in conclusies uit definities! Het is niet dynamisch, het past niet op een bewegende werkelijkheid, het is "statisch".

Het Bijbelsche denken daarentegen is door en door dynamisch, het werkt daarom met qualificaties en $z$ iet al het gebeuren als h is t or i e. Vandaar dat het probleem wat "geschiedenis" eigenlijk beduidt, voor de hedendaagsche theologische situatie zoo scherp-actueel wordt. Het Grieksch-Westersche denken is nog altijd statisch en definieerend en ziet—onbewust vaak-alles als één groote mech a n i e k. Dat die mechaniek draait, interesseert den onderzoeker niet ernstig, immers hij tracht slechts uit te vinden wat de deeltjes van dat klokwerk zijn en hoe die in elkaar grijpen.

De nieuwste natuurwetenschap is nu, zonder dat zij dat gezocht heeft aangeloopen tegen de $\mathrm{g} \mathrm{r}$ e $\mathrm{n} \mathrm{s}$ van het gebied, waarbinnen de werkelijkheid grof genoeg is om zulke denkgewoonten toe te laten. Het atoom is zoozeer tot een raadsel geworden, dat zijn laatste „bestanddelen" niet meer materiaal te noemen zijn. Alleen wiskundige formules en beeldspraak helpen hier nog, als men het hulp kan noemen, dat men een atoom voorstelt als iets, dat op ons zonnestelsel gelijkt. De „zon” en de "planeten" daarvan zijn echter, als men tot het laatste komt, niet meer stoffelijk te noemen. Kracht en stof zijn al even mysterieus geworden als wat wij vanouds ,geest" hebben genoemd: wij zijn an de grens gekomen van de mechaniek-voorstelbaarheid, want ook die zonnestelselvoorstelling is maar een beeld voor iets, dat nog slechts met wiskundige symbolen is te hanteeren. Een synthese tusschen Plato of Aristoteles en het Bijbelsche denken, ook al was zij een gemodernizeerde vertolking 
van de gedachte der Reformatoren, zal onvoldoende blijken om zulke redenen. De verhouding echter tusschen Exegese en Dogmatiek zal opheldering blijven eischen. Die zal a llereerst moeten komen van den kant der Exegese, terwijl de Dogmatiek zich van het menschelijkbepaald zijn harer uitspraken meer bewust zal moeten worden en meer zal moeten rekenen met het feit, dat ook het logisch vermogen van den mensch een vermogen van den $z$ ondige $n$ mensch blijft. Ook zij heeft haar grenzen!

Volgens haar eigen getuigenis berust de Dogmatiek overwegend op Exegese. De exegeet heeft echter om te kunnen gaan werken onontwijkbaar een zeker voorafgaand, voorlopig inzicht en overzicht noodig. Dat overzicht zal heel licht sterker saamhangen met zijn eigen dogmatiek dan hij bewust weten kan! Hier dreigt dus een circulus vitiosus, een kringredeneering. Immers, de exegeet $\mathrm{m}$ o e $t$ congeniaal zijn met den auteur en dat beteekent hie r, dat hij het openbaringsgetuigenis der N.T.-ische schrijvers moet kunnen zien als een bizondere daad en beschikking van den Levenden God, den Oppersten Wil. Maar hij mag in geen geval aan de Schrift opdringen wat de locus de Scriptura van zijn eigen Hervormde, Neo-calvinistische, Anglicaansche, Grieksch-Orthodoxe of Roomsche dogmatiek zegt! Integendeel, hij moet - dat is zijn fundamenteele taak! - de Schrift aan hém la te $\mathbf{n}$ zeggen wat $z$ ij op dit punt te zeggen heeft, niets meer en ook niets minder! Wij spreken van de Schrift, want het Nieuwe Testament b.v. is niet maar een in en door de historie tot stand gekomen bundel, maar het is een ge estelijke e e n he id, d.w.z. de uiting van aan al zijn auteurs gemeenschappelijke geloofsovertuigingen. Het eigene der auteurs - waar en als het aantoonbaar is - is vervat in dat geheel en dat geheel is als g e h e e l méér dan zijn deelen.

$\mathrm{Da}$ : feit moet de exegeet erkennen en in rekening brengen, maar tevens zich er streng voor hoeden, dat hij zijn eigen formuleeringen in zake canon en inspiratie niet in de plaats stelt van wat bij den auteur in werkelijkheid aanwezig is.

Zoo is ook de geheele Schrift niet maar een "historisch geheel"! Wijlen Dr. A. Kuyper schreef daarvan ergens: „, de Bijbel ontstond en werd voltooid als een organisch in elkaar sluitend goddelijk kunstwerk". Hij verzet zich dan tegen de in zijn dagen heerschende historistische exegese en uitlegging, die "de Schrift interpreteerde op een wijze, dat zij juist als Schriftuur vernietigd werd". Daar had hij gelijk in en ook vele anderen zagen dat in, die hem niet volgden op zijn particuliere wegen.

Doch i edere formuleering van het Schrift-feit, waarmede de exegeet of de uitlegget bewust of onbewust werkt, moet in zijne handen, terwijl hij a a n he $t$ werk is, blijven wat zij dán is, een wer khy pothese aangaande het inzicht, dat bij den auteur aanwezig was, toen deze neerschreef wat wij thans voor oogen hebben. Overal moet 
het schriftuur-karakter der Schrift den exegeet voor oogen staan, maar actueel wordt het alleen dáár, waar er objectieve aanleiding toe bestaat. Zoodra wij echter feiten van d e z e $\mathrm{n}$ aard, die wij als congeniaal-herkenbare gegevens bij den auteur aantreffen, in de Schrift ontmoeten en die anders dan als werkhypothese gaan aanvatten, treden wij buiten onze taak! Dan verwisselen wij ze met een stelling uit de ,systematische" theologie: dan wordt de exegeet dogmaticus en raakt al heel gauw in kringredeneeringen. Het is de eigenaardige taak der Dogmatiek om zulke gegevens, in hun geheel overzien en uitgelegd, tot stellingen te maken. Die stellingen zal zij dan ook hebben te $\mathrm{h}$ e $\mathrm{r} z$ i e $\mathrm{n}$ als betere exegese haar duidelijk maakt, dat haar gegevens gebrekkig waren of onjuist waren geinterpreteerd.

Voor den exegeet treedt het gevaar der cirkelredeneering haast onvermijdelijk op, wanneer hij vergeet, dat het he r m e n e u t is ch onge o orloofd is om, de begripsvormen, waarin men tegenwoordig over de in den text anwezige geestelijke feiten nadenkt en discussieert, te importeeren bij de studie van den auteur, als deze die $\mathrm{n}$ i e $t$ (of in anderen vorm en samenhang) gekend heeft!1)

Dit alles geldt ook voor den uitlegger. Onder hen, althans halverwege tusschen hen en den dogmaticus, bevindt zich de geleerde, die als makelaat deze zaken doorgeeft en het meest geraadpleegd wordt. Dat is de schrijver van de z.g. theologia biblica. Hoe hij zijn taak ook moge opvatten, hij zal in staat moeten wezen over de zuiverheid en goede trouw der exegese een welgegrond oordeel te hebben, dat berust op groote kennis van zaken. Maar ook de systematicus of dogmaticus is zelf tot een niet mindere mate van oordeelsbevoegdheid verplicht. Aan dien eisch voldoet allerlei hedendaagsche "nieuwe" dogmatiek niet altijd!

Voor een deel valt de verantwoordelijkheid daarvoor op de exegeten. De exegeet moet n.l., wanneer de uitlegger, de dogmaticus, de kerkelijke leider bij hem aankloppen, hen niet tot het slachtoffer van kringredeneeringen maken, al zouden zij ook nog zoo tevreden zijn over

1) Er ligt een heel groot gevaar in het onderschatten van het verschil, dat onze Christenwereld scheidt van de Joodsch-Grieksch-Oostersche in het heidensche milieu van de le eeuw. Er ligt nogmaals een groot gevaar in het onderschatten van den invloed van zoovele eeuwen van Westersche theologie en beschaving op den gedachtengang en de stempeling van het denkmateriaal. Niet alles wat wij vanzelfsprekend, redelijk en natuurlijk vinden, is dat altijd geweest en is het ook niet in werkelijkheid. W'at die ,stempeling" betreft: wie is in staat zoo maar op te zweven en zich te verheffen boven de invloeden van nationale, kerkelijke, wijsgeerige en persoonlijke eigenaardig. heden en van zulk een ingewikkeld verschijnsel als het denken van een menschelijken geest. Toch moet dat, zooveel mogelijk, want het gaat om wa a $\mathrm{h}$ e id! Reeds de Apologeten dachten op geheel andere wijze dan de Apostelen! Als men b.v. de beeldsprakige uitdrukkingen onderzoekt, waarmede zij de ,kerkidee" hanteeren, wordt dat heel duidelijk! Nog duidelijker wordt dat bij de vaders der theologie: Clemens Alexandrinus, Origenes, Athanasius, Augustinus, gezwegen nog van Philo en de groote Gnostieken. 
wat hij hun voordroeg. Hij heeft slechts aan ieder van hen duidelijk te laten zien, wat het precies is, dat zij willen vertolken in de terminologie van ons geslacht. Hij mag zich door hen niet laten verleiden tot het opleggen van die terminologie aan de Schrift.

Tenslotte iets over Exege se e $\mathrm{K} \mathrm{Kerkelijke} \mathrm{Le} \mathrm{e} \mathrm{r.} \mathrm{Stellen}$ wij het geval, dat een exegetisch onwraakbaar resultaat in strijd is met een bepaalde leerstellige uitspraak van een bepaalde kerk. Op het erf der Reformatie mo et dan de dogmatiek wijken voor de Schrift. Bij Rome is dat practis ch niet het geval. Men heeft daar procedures ontwikkeld, waardoor het kerkelijk ,gezag" kan ingrijpen en de beslissing kan onttrekken aan het hermeneutisch geweten van exegeet en uitlegger. Besliste uitspraken der Schrift kunnen aldus onvruchtbaar worden gemaakt. Wanneer Rome gesproken heeft, is de zaak uit: zoowel de exegeet als de dogmaticus, die hem gevolgd was, kunnen het buiten discussie gestelde punt alleen nog maar als een ,verworpen dwaling" toelichten. Of zijzelve die ,dwaling” inzien, doet niet ter zake, mits zij maar gehoorzamen! Natuurlijk wordt dan op den duur de leer der exegese, de z.g. hermeneutiek, scheefgetrokken ten behoeve van het voorkomen van dergelijke ,dwalingen”.

In de kerken der Hervorming komen conflicten tusschen kerkelijke leer en schriftuitlegging zelden voor, omdat de belangrijkste verschillen in den loop der eeuwen reeds geleid hebben tot spontane vorming van bizondere kerkgenootschappen of secten. Van veel grooter gewicht is echter het feit, dat geen dezer kerken zich beroept of kan beroepen op eenig haar in 't bizonder verleend ,gezag" in zake exegese en dogmatiek, dat zulk een gezag daar evenmin opwassen kàn uit de hooge oudheid eener opinie, uit het antal harer voorstanders of uit welk uiterlijk motief ook. Geen organisatie, van welken aard ook, waarborgt de medewerking des Hl. Geestes. De Schrift kent geen „kerkelijk” organizeerbaar gezag van dezen aard: e en , kerk"kan evengoed dwalen als e en enkeling, de traditie evengoed als een nieuwlichter, als het gaat over exegese en dogmatiek op punten, waar inderdaad verschil van oordeel bestaan kan.

Hoe kan dan het gevaar van $s u b j e c t$ ivis $t$ ische $S c h r i f t-$ u it legging worden geweerd? Rome heeft de ,gezags"-methode gevolgd en het beroep op de Schrift practisch uitgeschakeld. Dat is een voor de hand liggende en waarschijnlijk noodzakelijke consequentie van zulk een aanmatiging van gezag. Op Reformatorisch terrein is dat uitgesloten. Het testimonium Spiritus Sancti is niet aan kerkvergaderingen verleend.

Christelijke schriftgeleerden mogen lid zijn van welke kerkvergadering of kerkelijke commissie men maar wil, zij kunnen daaraan nimmer eenig ,gezag" ontleenen in zake het verband tusschen exegese en dog- 
matiek. Christus is het Hoofd der Kerk. Hij laat Zich niet monopolizeeren door eenig aardsch instituut of door eenige vergadering van zulken oorsprong.

Toch is er in deze moeilijkheid voorzien. Immers, doordat de HI. Schrift in aller handen is en doordat competente uitleggers overvloedig zijn en de kerken tot dusver ervoor hebben gewaakt, dat zulks het geval blijft, is de schriftmatigheid der leer $\mathrm{ge} \mathrm{w}$ a a r borgd door een organische reactie vanuit het geheel der geloovigen.

Dat proces werkt veel langzamer dan b.v. de Roomsche gezagsmethode, maar het brengt mede, dat ook een eventueel waarheidsgehalte in een opgekomen dwaling niet licht verloren gaat. Kerkelijke vergaderingen kunnen dan ook slechts uitspreken (wanneer het n.l. noodzakelijk is zoo iets te doen) wat reeds door dat proces voldoende duidelijk is geworden. $\mathrm{Zij}$ kunnen het ook alleen doen onder voorbehoud van latere herziening en zelfs van cassatie. Immers, zij kunnen $n$ o o i t haar getuigenis in de plaats stellen van dat des Hl. Geestes of aan haar "wettig" saamgesteld zijn en haar „,bevoegdheid" eenig recht tot spreken in deze zaken ontleenen, dat niet zou moeten wijken voor het schriftuurlijk licht, dat de Heer der Kerk laat doorbreken onder de gcloovigen.

De Christelijke schriftgeleerde, d.w.z. de vakkundige exegeet en uitlegger, heeft derhalve voor de erkenning zijner resultat en in de Dogmat i e k te wachten op de erkenning, die door het testimonium Spiritus Sancti onder de geloovigen wordt tot stand gebracht. Voorbarige uitspraken van „kerkelijke" commissies of autoriteiten moet hij niet zoeken.

Hij zal dat ook niet willen doen, want het is met het getuigenis der Sंchrift tenslotte niet zóó gesteld, dat een hedendaagsch Bijbellezer geen stap zou kunnen verzetten zonder de meest uitgebreide, consciëntieusdeskundige en desnoods ook ,kerkelijk"-gewaarborgde voorlichting! Wat de Reformatoren leerden over de perspicuitas Sacrae Scripturae, d.w.z. de helderheid der Schriften in de dingen, di e den geloovige a a nga n als geloovige, blijkt in het leven nog altijd proefhoudend te wezen.

W'anneer de Dogmatiek zich als haar allereerste taak stelt om, rekenende met het Bijbelsche denken, systematisch te ontwikkelen, wat de exegeet en uitlegger op grond van competente studie te zeggen heeft over $\mathrm{d}$ e $z \mathrm{e}$ dingen, zal de verhouding tusschen Exegese en Dogmatiek geen zorgen baren.

Het is hier de plaats voor een enkele slotopmerking. Ook de tijd, dien wij beleven, en het nieuwe tijdperk der atoomenergie, dat wij binnentreden, heeft met dit alles te maken. De ontwikkeling der natuurwetenschappen lijkt, oppervlakkig bezien, gunstig voor hetgeen ons bindt. De gedachte van Schepping en Schepper, van een fundamenteelen Wil als grond aller dingen kan niet zoo gemakkelijk meer terzijde worden 
geschoven. Ook op het terrein der eigenlijke wijsbegeerte gaat dat niet zoo gemakkelijk meer. De eschatologische gedachte, wereldondergang en oordeel, krijgt ook gunstiger gehoor. Die dingen zullen, binnen een aantal jaren, denkelijk in dán weer verouderden vorm, tot de massa doordringen. De vorm van ,ongeloof”, die voor de XIXde eeuw karakteristiek was, en die nu nog doorwerkt, zal dan eindelijk verouderd zijn. Nieuwe en geduchter vormen zullen echter verrijzen. Omdat de naïeve vereenzelviging van Humanisme en Christendom haar einde tegemoet gaat, zal de vraag naar het verband van Dogmatiek en Ethiek, van Paulus en de Evangeliën, ook exegetisch zeer belangrijk worden.

Omdat het onderzoek van de ,psychische" sfeer langzamerhand eenige resultaten gaat leveren, zal de Kerk komen te staan tegenover de theorieën van een verfijnd materialisme, als men het zoo nog zal kunnen noemen. Als niet het besef van ,zonde”, d.w.z. van het ingaan tegen den fundamenteelen Wil, bij individu en massa weer een angelegenheid van den allereersten rang wordt, komt straks de Kerk met haar boodschap van verlossing en met haar nadruk op den uiteindelijken $z$ in van het leven en van de geschiedenis wellicht te kloppen aan een deur, waarachter men wel discussieert over fundamenteele zaken, maar dat doet in woorden en voorstellingen, die haar vreemd zouden zijn, zelfs als er aangeknoopt wordt bij de taal der Schrift.

Aanvallend optreden eischt van een leger thans heel wat meer en vaak heel wat anders dan in den tijd der Reformatoren. Ook op geestelijk terrein geldt dat!

Wij staan aan de poort van een nieuw tijdperk! Als de eerste troebelen voorbij zijn en de adaptatie op staatkundig en maatschappelijk terrein, met of zonder groote rampen, bereikt zal wezen, is er voor den gemiddelden mensch over de lengte en breedte der aarde, dank zij de atoomenergie en de vervanging van industrieele anarchie door toenemende ordening, een groote mate van veiligheid en stoffelijken voorspoed te wachten. Ook de oppervlakkige „beschaving” en het gezag van de halfgeleerden zal dan toenemen! Meer dan ooit zal dus de Kerk theologen van reformatorisch formaat noodig hebben. Meer dan ooit zal hun taal huius temporis moeten wezen! Meer dan ooit zal de Schrift recht moeten worden verstaan en zal de verhouding tusschen Exegese en Dogmatiek actueel worden.

Leiden

J. DF ZWAAN 